\title{
Lo que el tiempo no se llevó: la atemporalidad de la declaración de oficio de la nulidad del acto jurídico
}

\author{
Jose Luis Rodriguez Vallejos ${ }^{1}$, Franklin Enrique Chávez Torres ${ }^{2}$
}

\begin{tabular}{|c|c|}
\hline INFORMACIÓN DEL ARTÍCULO & RESUMEN \\
\hline $\begin{array}{l}\text { Historia del artículo: } \\
\text { Recibido el } 26 \text { de noviembre de } \\
2020 \\
\text { Aceptado el } 22 \text { de diciembre de } \\
2020\end{array}$ & $\begin{array}{l}\text { En el presente artículo se analiza la situación problemática recaída en la } \\
\text { posibilidad de otorgarle plazo prescriptorio a la potestad del juez de declarar } \\
\text { de oficio la nulidad de oficio de un acto inválido; es decir, de hacer extensiva } \\
\text { las reglas contenidas en el numeral 1) del artículo } 2001 \text { del Código civil de } 1984 \\
\text { al juez como director del proceso. Se determina que no es posible realizar dicha }\end{array}$ \\
\hline \multirow{3}{*}{$\begin{array}{l}\text { Palabras claves: } \\
\text { prescripción extintiva } \\
\text { potestad del juez } \\
\text { nulidad de oficio } \\
\text { invalidez absoluta } \\
\text { convalidación }\end{array}$} & $\begin{array}{l}\text { contienen fundamentos iguales, así también por no existir previsión legal } \\
\text { respecto al plazo para el ejercicio de la potestad nulificante, lo que conlleva a } \\
\text { atender la no convalidación de los actos jurídicos nulos. }\end{array}$ \\
\hline & $\begin{array}{l}\text { Not gone with the wind: the timelessness of the judge's declaration of } \\
\text { the legal act nullity }\end{array}$ \\
\hline & ABSTRACT \\
\hline $\begin{array}{l}\text { Keywords: } \\
\text { extinctive prescription } \\
\text { power of the judge } \\
\text { nullity of office } \\
\text { absolute invalidity } \\
\text { validation }\end{array}$ & $\begin{array}{l}\text { The present article analyses the problematic situation regarding the possibility } \\
\text { of giving a limitation period to the judge's power to declare ex officio the nullity } \\
\text { of an invalid act; that is, to extend the rules contained in numeral 1) of article } \\
2001 \text { of the Civil Code of } 1984 \text { to the judge as director of the process. It is } \\
\text { determined that this extension is not possible because the prescriptive } \\
\text { phenomenon and the nullifying power do not have equal grounds, and also } \\
\text { because there is no legal provision regarding the time limit for the exercise of } \\
\text { the nullifying power, which leads to the non-convalidation of the nullified legal } \\
\text { acts. }\end{array}$ \\
\hline
\end{tabular}

\section{Introducción}

Dentro de un sistema procesal civil plagado de inconsistencias conceptuales, podemos hallar, dentro de las denominadas prerrogativas del juez, el poder atribuible a aquél de dirigir el proceso encausándolo dentro del sendero que lleva al respeto de los derechos de rango constitucional, aplicando de manera obligatoria el derecho al caso en concreto sobre la base del principio iura novit curia, "pues en este componente no existe condición alguna, y el juez es libre de elegir el derecho que cree aplicable, según su ciencia y su conciencia" (Couture, 1958, p. 258), por la independencia otorgada por el sistema en sí.

Como bien manifestaba Morales (2010):

\footnotetext{
${ }^{1}$ Investigador independiente, Abogado por la Universidad Católica Santo Toribio de Mogrovejo, Chiclayo, Perú. Email: jose.rodriguezv@pucp.edu.pe. ORCID: https://orcid.org/0000-0002-6447-8949

${ }^{2}$ Investigador independiente, Abogado por la Universidad Señor de Sipán, Chiclayo, Perú. Email: fchaveztorres@outlook.com. ORCID: https://orcid.org/0000-0002-0774-8682
} 
IUS Vol. 9. $N^{\circ} 2$ (2020): 5-17

La independencia de los jueces tiene que plasmarse, concretamente en cada caso, cuando interpretan las normas. El juez boca de la ley no es precisamente la mejor demostración de la independencia del juzgador. Tiene que existir una suerte de valor agregado que el juzgador le otorga a la norma, al momento de resolver un caso. (p. 24)

En ese orden, atendiendo a que en doctrina no se encuentra zanjado el tema, al punto que no existe mayor profundización sobre el mismo, mediante el presente trabajo se determinará si el juez, para conocer de oficio la nulidad de un acto jurídico, tiene o no límites temporales dentro de la regulación civil peruana, cuando este no ha sido promovido por las partes de una relación jurídica procesal. En tal sentido, se detallarán conceptos generales de las instituciones jurídicas vinculadas al tema del presente trabajo, mediante una investigación cualitativa y que comprenda los métodos comparativo, exegético y dogmático.

No es un secreto que, dentro de los límites que nuestra legislación expone se encuentra el de la congruencia, entendida ésta como el límite del juez para resolver un determinado conflicto de intereses o eliminar una incertidumbre jurídica dentro de los parámetros entiéndase pretensiones- expuestos por las partes; sin embargo, como veremos en el desarrollo del presente, aquél límite que encierra al juez a lo propuesto en el proceso puede ir más allá cuando existe colisión entre la seguridad jurídica y legalidad.

Así pues, se advierte la problemática del límite temporal que tiene el juez de declarar de oficio la invalidez del acto jurídico cuando este no haya sido invocado por las partes dentro de sus pretensiones, máxime si el tiempo que ha transcurrido desde la celebración -del acto viciado- hasta el conocimiento del juez de esta anomalía estructural ha superado los 10 años; es decir, la facultad que tenía el titular del derecho sustantivo de demandar ha prescrito.

La situación controversial radica en la posibilidad de aplicar este plazo prescriptorio al juez que conoce esta situación patológica del acto, y como tal, verse en la imposibilidad material de declarar la nulidad de este (entiéndase del acto). 0 , por el contrario, sobre la base de la seguridad jurídica que implica el impedimento de investir de legalidad a un acto viciado, declarar la nulidad de oficio pese a haber excedido el plazo prescriptorio para materializar, a cargo del titular del derecho sustantivo, aquella pretensión.

\section{Consecuencias del transcurso del tiempo en el derecho}

Es preciso iniciar el desarrollo del presente apartado manifestando que, el derecho, como creación del hombre para la regulación y control de las conductas de su especie, se encuentra -irremediablementesometido al factor tiempo. Del mismo modo, tiene incidencia directa en la propia existencia del hombre desde el momento de su concepción hasta el fin de aquél con la muerte, e incluso, después de ella. En consecuencia, tanto la vida misma, como el derecho y la ley, tienen una influencia directa del transcurso del tiempo, ya sea a través de la evolución de conceptos de instituciones jurídicas, situaciones fácticas, como en la delimitación de la aplicación de una norma y la vigencia que debe tener ésta en el ordenamiento.

En ese orden de ideas, podemos afirmar que, como elemento intrínseco del derecho mismo, el transcurso del tiempo puede manifestarse de distintas formas, ya sea a través del término, el plazo, la prescripción o la caducidad (Linares, 2007); pues, como es de verse, en la realidad jurídica material estas formas de materialización del transcurso del tiempo conllevan, sin duda alguna, a la creación de efectos jurídicos dentro de la esfera de los derechos subjetivos de las personas, ya sea por no promover determinado acto procesal en el momento que deba realizarse, o por ejercitarlo una vez vencido el lapso de tiempo otorgado por el órgano competente. Frente a estas situaciones de hecho podemos asegurar que la consecuencia jurídica inmediata es la pérdida de la oportunidad de obtener un pronunciamiento sustancial sobre el conflicto de intereses o incertidumbre jurídica que se haya promovido, perdiendo relevancia si se tiene o no la razón en la pretensión planteada. Claro está que existen excepciones a esta regla general, como es el supuesto de pretensiones que versan sobre asuntos de familia, aquello sobre la base de lo establecido en el Tercer Pleno Casatorio Civil que constituye precedente de observancia obligatoria por mandato expreso del artículo 400 del Código Procesal Civil, siendo ésta la excepción a la regla general antes precisada.

Por otro lado, el devenir del tiempo puede, además, otorgar derechos con el solo cumplimiento de ciertos presupuestos y requisitos por un determinado período, generalmente, previsto en la norma sustantiva. Tal es el caso de la prescripción adquisitiva de dominio o usucapión que, sin entrar a analizar a fondo su naturaleza jurídica, se puede afirmar que es la forma de 
adquisición de derechos reales con el solo cumplimiento de determinados presupuestos materiales por un período de 5 o 10 años según sea el caso. Sin embargo, en la acera de al frente tenemos a una institución jurídica que estructura la base del presente trabajo: nos referimos a la prescripción extintiva que, a diferencia de la usucapión, trae como consecuencia ipso iure, la pérdida de la oportunidad de hacer valer los derechos subjetivos a través de la materialización del derecho de acción mediante la pretensión. Dicha pérdida se funda en el transcurrir del tiempo que también lo otorga la norma. En el caso peruano, regulado en el artículo 2001 del Código civil de 1984, tal y como desarrollaremos a continuación.

\section{La prescripción extintiva}

\subsection{Naturaleza jurídica}

Como hemos precisado, el decurso -en el derechotiene como consecuencia el nacimiento y pérdida de algunos derechos. Uno de estos es la posibilidad de recurrir a un tercero a través de la heterocomposición, ya sea judicial o extrajudicial, para la solución de un conflicto de intereses o para eliminar una incertidumbre, ambas con naturaleza jurídica. Es decir, el devenir del tiempo tiene como consecuencia, castigar la inacción del titular del derecho material por no ejercitar este -derecho- dentro del tiempo permitido por ley.

Ahora bien, en la legislación peruana no existe un concepto de lo que es la prescripción extintiva. No se puede soslayar el hecho que un Código Civil no debería estar diseñado a contemplar definiciones, pues estas implican darle un criterio cerrado a algún concepto, cuando este debe sujetarse a una interpretación evolutiva; máxime si su alcance debe ser general.

Es verdad que la ley civil no se configura como un tratado o manual de Derecho. Pero ello no significa que sus preceptos solo puedan estar al alcance de unos pocos. Aquí recogemos al apotegma del eminente Manuel Augusto Olaechea, quien expresaba que la ley debía enseñar. (Osterling, 2007, p. 12)

Sin embargo, de la redacción del Código civil de 1984, se advierte una clara referencia a que la prescripción ataca directamente el derecho de acción, ya sea este personal, real, la que nace de una ejecutoria, del acto jurídico, etc., cuando ésta no es, per se, su verdadera naturaleza jurídica. No comulgamos así con la esencia del concepto de la prescripción en el Código Civil peruano, en la medida que, lo que ataca la prescripción extintiva no es la acción en sí misma, pues ésta constituye el poder jurídico abstracto que tiene toda persona de solicitar tutela jurisdiccional; sino, la pretensión materializada a través del derecho de acción; es decir, debe entenderse a la acción como el instrumento abstracto para materializar el derecho sustantivo a través de la pretensión. En esa línea de definición, Alsina (1981) sostiene que la prescripción extintiva es de carácter procesal, mientras que la prescripción adquisitiva es de naturaleza sustancial, en la primera se solicita la extinción de una pretensión procesal que se halla respaldada por un derecho sustantivo.

Asimismo, la profesora Ledesma (2008) manifiesta que:

La prescripción no es un medio de extinción, ni de la acción ni del derecho subjetivo, sino de la pretensión. No significa la prescripción que algo nazca con un plazo de vida, sino que, si durante determinado tiempo está inactivo, no se puede luego imponer. (p. 474)

Entonces, queda dilucidado que la esencia de la prescripción extintiva es la de un mecanismo que castiga la inacción del titular del derecho sustantivo por no acudir al órgano competente a efectos de materializar su pretensión a través de su escrito postulatorio, extinguiendo como tal la pretensión, no así la acción como mal ha sido señalado en nuestra Código civil.

Es cuestionable, entonces, la noción de prescripción contenida en el citado texto normativo, por cuanto la idea de acción evoca un derecho subjetivo que no estaría vinculada a dicha figura, sino a la de caducidad, y lo que en todo caso debe entenderse como prescriptible es la pretensión. Así, se sostiene lo siguiente:

En efecto, las nociones incorporadas a los artículos 1989 y 2003 hacen referencia a la acción en su acepción jurídica tradicional, como un concepto integrado al del derecho subjetivo y no como un derecho subjetivo propio y autónomo, como es el derecho de acción, que debe entenderse como el derecho a la jurisdicción, o, si se prefiere, como el derecho a la tutela jurisdiccional. (Vidal, 2014, p. 123) 


\subsection{La prescripción extintiva en la norma sustantiva}

En el entendido que la prescripción extingue la pretensión, lo que no se extingue es el derecho que emana de ella. Tal es así que el sujeto pasivo está facultado para alegar la falta de ejercicio de la misma y, por tanto, detener la operatividad del mecanismo judicial; o en todo caso, renunciar a dicha invocación, ocasionando que el proceso continúe su trámite hasta la emisión de una decisión de fondo.

Una reciente ejecutoria suprema nacional enuncia la caracterización de la prescripción extintiva:

Tres son las características de la prescripción extintiva: el transcurso del tiempo, la inactividad de la parte titular del derecho subjetivo y la falta de reconocimiento del sujeto pasivo de la relación jurídica. El primer requisito, como se advierte, es un hecho natural en el que, sin embargo, interviene el legislador para establecer un inicio y un final para el cómputo respectivo. Los otros requisitos tienen que ver con el comportamiento que los sujetos de la relación jurídica tengan, ya porque optaron por el "silencio" de su derecho, ya porque invocaron ese silencio y el plazo señalado por ley para promover la inexigencia de la pretensión.

Estas características se alinean con la regulación de la prescripción extintiva en el Código Civil peruano. El hecho natural del transcurso del tiempo está delimitado por los plazos establecidos por el legislador en el artículo 2001. La inactividad de la parte titular del derecho subjetivo está demarcada por el cómputo del plazo prescriptorio, lo que según el artículo 1993 del citado Código, comienza a correr desde que se puede ejercer la acción (entendida como pretensión), y continúa incluso con los sucesores del titular del derecho. Por otro lado, el beneficiario de la prescripción extintiva puede invocarla o renunciar expresa o tácitamente a ella, pues se trata de una discrecionalidad de la parte integrante de la relación jurídica, proscribiéndose al juez declarar de oficio dicha figura sin sustentarse en la alegación de parte.

Los plazos de prescripción pueden ser suspendidos o interrumpidos. La suspensión versa sobre "el detenimiento del tiempo, es decir, el plazo que se viene desarrollando se detiene, no se toma en consideración mientras dure la situación -señalada por ley- por la cual no se computa dicho tiempo transcurrido" (Morales, 2007, p. 234). La interrupción, en cambio, plantea que el tiempo transcurrido no sea considerado, generando que nuevamente inicie el cómputo del plazo prescriptorio.

El fenómeno de la prescripción solo se concreta con la alegación de una parte, quien, beneficiada por ella, denota cierto interés en su invocación y posterior amparo por el órgano jurisdiccional. A pesar que la Ley no haga referencia a los sujetos que pueden invocar la prescripción, puede sostenerse que la legitimidad en la invocación de dicho fenómeno no se circunscribe a las partes de la relación material o sustantiva, sino que se extiende a terceros que intervienen en el proceso y manifiestan interés en el resultado del mismo porque atañe a sus derechos. Así, son ilustrativos los casos en donde opone prescripción "el tercero propietario de los bienes hipotecados o prendados en garantía de deudas ajenas; el codeudor solidario, el causahabiente de aquel que ha adquirido en virtud de un negocio anulable, respecto de la acción de anulación del negocio mismo" (Ariano, 2007, p. 207).

\subsection{La prescripción extintiva en el derecho comparado}

En Francia, el Código Civil de 1804 ha sufrido variaciones. Así, por ejemplo, de un plazo de treinta años para la prescripción extintiva y la usucapión, se pasa a un plazo de cinco años para el ejercicio de acciones personales (artículo 2223). Si bien su artículo 2227 establece que el derecho de propiedad es imprescriptible, la acción real inmobiliaria tiene un plazo de prescripción de treinta años. Existen, además, otros supuestos de prescripción con plazos cortos o medianos, como son la acción de responsabilidad contra representantes de personas en un proceso judicial (cinco años según artículo 2225), acción derivada de responsabilidad por daño personal (diez años según artículo 2226), acción de responsabilidad por daño ecológico (diez años según artículo 2226-1).

Es importante considerar los supuestos de suspensión e interrupción. Se ha establecido que con la suspensión no se afecta el periodo transcurrido (art. 2230), a diferencia de la interrupción, que borra dicho término e inicia nuevamente (art. 2231). A propósito de esto, en el caso peruano, si bien es cierto hay una interrupción temporal con la suspensión, pero se dispone la sumatoria del periodo transcurrido en la reanudación, es decir, cuando desaparezca la causa de suspensión. Tal vez un aspecto relevante que no está recogido en nuestra normativa nacional es la suspensión cuando las partes acuerden por escrito solucionar sus conflictos a través de la mediación o conciliación (Art. 2238), 
encontrándonos solamente con el supuesto de suspensión cuando se presenta la solicitud de conciliación extrajudicial.

El legislador civil francés prescribe que el término o plazo de prescripción puede estar sujeta al acuerdo de las partes, es decir, estos pueden reducir o ampliar el plazo de prescripción establecido en la norma (primer párrafo del art. 2254), aunque no se puede reducir a menos de un año o superar los diez años. Incluso pueden adicionar causales de suspensión o interrupción de la prescripción (segundo párrafo del art. 2254). Esta situación no se presenta en la normativa civil peruana, por cuanto los plazos de prescripción son establecidos por el legislador y son inmutables, y respecto a los supuestos de suspensión e interrupción, se trata de un listado que no está a disposición de las partes para el aumento de supuestos, toda vez que se requiere concesión legal.

En el Código Civil italiano es expresa la referencia a la inaplicabilidad de la prescripción cuando se traten de derechos indisponibles (art. 2934), aspecto que no se acoge en el Código peruano. El artículo 2936 del Código Civil italiano regula la nulidad de los acuerdos contrarios a las disposiciones de la prescripción, diferenciándose con la flexibilidad asumida en el Código Civil francés. Los supuestos de suspensión de prescripción del artículo 2941 son similares a los contemplados en el artículo 1994 Código Civil peruano, con la diferencia que este último acoge otros supuestos relacionados con la falta de representación legal de las personas con capacidad de ejercicio restringida, los concubinos o la imposibilidad de reclamar el derecho ante un órgano jurisdiccional. El artículo 2943 regula los supuestos de interrupción de la prescripción, que son acogidos por imitación en nuestra normativa nacional: reconocimiento de la obligación, citación con la demanda aun cuando el juez sea incompetente o cualquier otro acto con el que se notifique al deudor. Asimismo, el artículo 1998 del Código Civil peruano es imitación del artículo 2945 del Código Civil italiano, con relación a que la interrupción genera que el decurso inicie nuevamente en los supuestos de notificación con la demanda y petición hecha durante el proceso.

Se establece como regla general en la normativa italiana que la prescripción extintiva de derechos opera con el transcurso de diez años. También se regulan prescripciones con términos breves (artículos 29472953), estableciéndose plazos de cinco años para ejercer el derecho a indemnización de daños resultantes de hechos delictivos, prestaciones por renta perpetua o vitalicia y pensión alimentaria, así como prestaciones por arrendamiento de bienes inmuebles. Finalmente, se ubica la "prescrizione presuntiva", que recoge supuestos de prescripción extintiva con plazos aún más cortos, de seis meses, un año y tres años.

En la doctrina peruana se indica que el Código Civil alemán de 1900 (BGB) no estimó a "la prescripción como extintiva de derechos y, bajo la influencia de la pandectística germana, introdujo el concepto de pretensión como equivalente al de la actio romana, precisando que lo que prescribía eran las pretensiones generadas por el derecho subjetivo" (Vidal, 2014, p. 122). Se critica este comentario porque el BGB asume una concepción distinta de la pretensión respecto de la normativa peruana, pues en esta sería evidente la connotación procesal de dicha figura.

Esta diferencia no es absoluta. El Código Civil alemán acoge una doble funcionalidad de la pretensión: en la relación material (obligacional o real) al proteger y garantizar los derechos, y permitir la exigencia de estos en vía de acción. Por ello es que la pretensión "señala tanto la legitimación material como la posibilidad de ejercicio e imposición, por vía de acción de una exigencia específica de una determinada persona frente a otra" (Larenz, 2019, p. 205). Cuando el artículo 194 del citado Código, en su apartado 1, se refiere al derecho a exigir de otra persona una acción u omisión, y en su apartado 2, a las controversias suscitadas en las relaciones jurídico-familiares, se está configurando la pretensión misma como consecuencia de las relaciones de derecho, razón por la cual el legislador ha considerado que puede estar sujeta a prescripción, a excepción de los supuestos contenidos en el apartado 2.

Las pretensiones que derivan de las relaciones obligacionales están sujetas a prescripción en el Derecho Civil alemán, con aplicación extensiva a otras pretensiones si es que fuera posible. El artículo 195 regula que el plazo ordinario o regular de prescripción es de tres años. Las pretensiones derivadas de los derechos sobre una propiedad prescriben a los 10 años, según el artículo 196. Asimismo, se tienen supuestos especiales de prescripción con plazo largo (30 años), como son las demandas por daños y perjuicios, las vinculadas a la restitución de la propiedad u otros derechos reales, los créditos ejecutables determinados en un procedimiento de insolvencia, entre otros contemplados en el artículo 197. 


\section{El acto jurídico}

\subsection{Elementos del acto jurídico}

Es menester delimitar, antes de iniciar el desarrollo del tema, nuestro concepto de acto jurídico. En ese sentido, concebimos al acto jurídico como el resultado del ejercicio de una potestad, que tienen los particulares, de regular sus intereses privados; es decir, es la expresión de la autonomía privada, entendida como la facultad que tienen las personas de relacionarse entre sí para la satisfacción de sus propias necesidades. Así, en línea con Betti (2018), sostenemos que es aquel acto con el que "el individuo regula por sí los intereses propios en las relaciones con otros (acto de autonomía privada), y al que el Derecho enlaza los efectos más conformes a la función económico social que caracteriza su tipo (típica en este sentido)" (p. 83). En ese orden de ideas, para la validez del acto se requiere, necesariamente, la concurrencia de elementos esenciales, los cuales ante su ausencia acarrean, indudablemente, su invalidez, y como tal, el cese de sus efectos jurídicos. Los elementos esenciales que establece el ordenamiento jurídico.

\section{i) Capacidad}

Debe entenderse este elemento como la del supuesto fáctico o jurídico de la realidad material de la persona en la medida que, indubitablemente, se pretende ambas situaciones para configurar un acto válido. Contrario sensu, si es que el acto adolece de la capacidad de sus celebrantes, simplemente, el acto en sí, no existe.

\section{ii) Objeto}

El objeto al que se refiere el Código civil, debe entenderse como el contenido esencial del acto jurídico; es decir, a la creación de aquel vínculo material entre los intervinientes, por un lado, la situación jurídica de ventaja, y por el otro, un supuesto de desventaja, con una consecuencia física y jurídicamente posible.

\section{iii) Finalidad}

En el caso peruano, la finalidad, como objetivo que las partes buscan con el acto jurídico, debe enmarcase dentro de la licitud. León (2019) esboza la forma de entenderse este elemento: "de forma subjetiva, si la indagación sobre la licitud se realiza en la conciencia del agente; de forma objetiva, si el juicio recae en el reglamento del negocio" (p. 76).

\section{iv) Forma}

Entonces, tal y como hemos precisado, los actos jurídicos, para su validez, requieren de la concurrencia perfecta de todos sus elementos; sin embargo, existen actos jurídicos que, aunados a estos elementos -estructurales- necesitan, además, de formalidades especiales para su validez, son los que doctrinariamente se les denominan ad solemnitatem, pues, la ausencia de aquella formalidad conlleva a la invalidez del acto.

\subsection{Nulidad del acto jurídico}

El acto jurídico es concebido desde una perspectiva bipartita; es decir, en la existencia de dos períodos endógenos sustanciales. El primero enfocado a los elementos de validez (elementos estructurales), y el segundo, a los efectos que están destinados a generar con su celebración (elementos funcionales). Sin embargo, en la práctica nos podemos enfrentar con supuestos de ausencia de efectos, o de validez del acto jurídico, lo que conlleva, de manera fehaciente, a la declaración de invalidez.

Tal y como hemos expuesto en el ítem anterior, la existencia de los elementos esenciales constituye, per se, la estructura funcional del acto jurídico; es decir, la ausencia de uno o más elementos, dentro de un determinado acto, deberá ser determinada por un tercero imparcial declarando la nulidad del acto jurídico, cuyo efecto será de naturaleza retroactiva, esto es, ex tunc. Dicho esto, podemos afirmar que la institución jurídica de la nulidad del acto jurídico constituye la contraparte patológica del acto jurídico en sí; sin embargo, no solo la inobservancia de estos elementos estructurales conlleva a la declaración de nulidad del acto, sino que el legislador ha considerado necesario determinar una serie de causales que, nosotros hemos considerado pertinente denominarlos: supuestos legales.

\subsubsection{Supuestos legales de ineficacia estructural del acto jurídico}

La premisa fundamental es aquella que define la invalidez del acto jurídico desde dos instituciones definidas, la nulidad y la anulabilidad del acto jurídico, en este apartado haremos referencia a la nulidad per se, en la medida que, el código civil peruano ha establecido, en su artículo $219^{\circ}$, una serie de supuestos fácticos cuya configuración constituye violación al orden público, tal y como desarrollaremos en el presente trabajo. Así 
pues, dentro de las denominadas causales de nulidad absoluta podemos advertir que éstas cuestionan directamente la ausencia de voluntad de los agentes, la contravención del objeto, la finalidad o el orden público, simulación absoluta, la inobservancia de la forma prescrita, la nulidad textual y virtual, como supuestos que conllevan a la invalidez del acto.

Es menester precisar que la configuración de los elementos normativos establecidos en el artículo $219^{\circ}$ del Código civil, acarrean, como consecuencia ipso iure, la nulidad absoluta del acto, sin lugar a convalidación o confirmación. Así pues, cuando hacemos referencia a la voluntad, consideramos que nos hallamos frente al primer elemento que debe contener el acto jurídico pues, es la creación de la ideación y el discernimiento (voluntad interna) el que da nacimiento a la expresión tácita o expresa (voluntad externa) del deseo de la persona para la configuración del acto jurídico, por tanto, si es que el acto jurídico adolece de estos supuestos abstractos o concretos, nos hallaremos, indiscutiblemente, frente a un acto jurídico inválido.

Sin embargo, no solo la ausencia de voluntad de los agentes acarrea la invalidez del acto, sino que, se evidencia que también debe declararse la nulidad cuando el objeto es jurídicamente imposible. Dicho esto, se debe entender este concepto delimitando la esencia del objeto del acto jurídico desde una perspectiva endógena - material. En ese orden, Escobar (2007a) manifiesta que:

El objeto del negocio jurídico es el conjunto de preceptos o reglas que la parte o las partes declaran "hacer suyas" con miras a conseguir un resultado práctico aceptado por el ordenamiento jurídico. Para que el objeto del negocio "alimente" a los efectos "negociales", es necesario que cumpla con ciertos requisitos normativamente impuestos, a saber: la posibilidad (física y jurídica), la licitud y la determinabilidad. El inciso bajo comentario establece, precisamente, qué es lo que ocurre cuando el objeto del negocio no cumple con dos de esos requisitos: la posibilidad (física y jurídica) y la determinabilidad. (p. 679)

Ahora bien, como hemos desarrollado en la introducción del presente trabajo, la finalidad de celebrar actos jurídicos responde a la necesidad de los particulares por satisfacer sus propios intereses, lo que conlleva a afirmar que todo acto jurídico tiene motivos precedentes que motivan a sus intervinientes a celebrarlo. Sin embargo, puede que la celebración de un acto jurídico obedezca a una finalidad ajena a la satisfacción de los intereses motivadores. En ese sentido, se tiene que los intervinientes, con una finalidad ajena a su naturaleza, celebran actos jurídicos que implican sustracción a una obligación u omisión legal, por lo cual su sola celebración contraviene la esencia de la finalidad del acto jurídico y su configuración debe castigarse con la invalidez del acto.

En cuanto a la simulación, nuestro Código Civil contempla tres supuestos. Empero, es relevante para la presente investigación considerar a la simulación absoluta, pues en específico este genera como consecuencia la nulidad absoluta. Se infiere como objetivo de las partes celebrar un acto jurídico que no es de común intención, es decir, se trata de un resultado fingido o no querido por los celebrantes. El legislador plasmó cómo debe comprenderse este supuesto en el artículo 190: "Por la simulación absoluta se aparenta celebrar un acto jurídico cuando no existe realmente voluntad para celebrarlo".

Respecto a la forma prescrita bajo sanción de nulidad, entendemos que versa sobre una exigibilidad legal del modo de exteriorizar la voluntad, esto es, reviste una forma específica y de carácter ineludible para la validez del acto. Taboada (1988) manifiesta lo siguiente:

Estos negocios jurídicos formales, denominados también solemnes o con formalidad Ad Solemnitatem, generalmente son negocios jurídicos de Derecho Familiar o Negocios Jurídicos Patrimoniales a título gratuito. Así, por ejemplo, en nuestro Código Civil son negocios formales el Matrimonio, la Adopción, el Reconocimiento de los Hijos Extramatrimoniales, el Testamento, la Donación de Bienes Muebles en algunos casos, la Donación de Bienes Inmuebles, el Mutuo entre Cónyuges, el Suministro a Título Gratuito, el Secuestro, la Fianza, el Compromiso Arbitral, la Renta Vitalicia, entre otros. (p. 76)

Y, no menos importante es la contravención del orden público, entendido este como la concurrencia copulativa de dispositivos normativos y principios que tienen como finalidad tutelar el normal comportamiento de las personas en la sociedad. Es por ello la importancia de esta institución en la medida que responde a intereses sociales, a través de la limitación de ciertos comportamientos con la única finalidad de hacer prevalecer los intereses generales por sobre los individuales. 
En tanto impone límites a la libertad humana, el orden público comporta normas de cumplimiento imperativo o ineludible, es decir, no está sujeto a disposición de los individuos, con la finalidad de garantizar la coexistencia social. Del tenor del artículo $\mathrm{V}$ del Título Preliminar del $C C$, se puede extraer que el enunciado "es nulo el acto jurídico contrario a las leyes que interesan al orden público" implica que toda norma de orden público debe estar previamente contenida en una norma legislativa para que trascienda su fuerza vinculante y la sanción ante la inobservancia. Sin embargo, precisamos que las normas de orden público son deducidas a través de métodos de interpretación, dando lugar a la nulidad virtual cuando el acto jurídico las contraríe; y de esta manera se le puede diferenciar con la causal de nulidad contemplada en inciso 7 del artículo 219 del CC, ya que esta implica una nulidad textual, esto es, cuando expresamente la ley fija la sanción ante su inobservancia.

\subsubsection{Legitimidad para invocar la nulidad}

Se menciona en doctrina que la nulidad de acto jurídico opera de pleno derecho y no requiere ser demandada, porque al ser inválido no genera efectos jurídicos. Por la práctica se sabe que dicha afirmación no es tan cierta, ya que muchos actos nulos sí terminan por producir efectos (por ejemplo, el título inscrito en Registros hace que el acto genere efectos registrales). Es por ello que "a las partes o a ciertos terceros les puede interesar que el juez reconozca, mediante una sentencia meramente declaratoria, que el negocio es nulo". (Escobar, 2007b, p. 689)

El primer párrafo del artículo 220 de nuestro Código Civil hace referencia a la alegación de la nulidad: extiende su invocación a cualquiera que tenga interés, incluyendo al Ministerio Público. Por su connotación procesal, esta parte evoca la legitimación para poder solicitar válidamente ante un juez la declaración de nulidad de un acto jurídico. Entendemos legitimación como el presupuesto procesal que "constituye la afirmación de la titularidad que debe realizar el demandante sobre el derecho o interés invocado, y la imputación de la obligación que debe realizar del mismo hacia el demandado" (Prado y Zegarra, 2018, p. 49).

Sin embargo, este concepto de legitimación debe ser abordado con mayor amplitud, comprendiendo a los terceros que tengan interés y al Ministerio Público. No solo las partes de la relación sustantiva están habilitadas para recurrir al juez, sino también los terceros que denoten un interés de carácter patrimonial o extrapatrimonial, en el contexto que con la decisión final (sentencia) obtendrán indirectamente un provecho o beneficio acorde al ordenamiento jurídico. Este supuesto es de legitimación ordinaria en cuanto el ordenamiento protege intereses legítimos que no se asocian a la titularidad de derechos que de suyo pueden invocar las partes de la relación material. Por tanto, con la situación de ventaja reconocida en la norma, superan un control de legitimación.

Caso distinto es la legitimación del Ministerio Público. Esta entidad u órgano constitucional actúa según las atribuciones conferidas por la Constitución y la Ley, garantizando que la ley sea aplicada en todo ámbito nacional. Discrecionalmente se le ha permitido entablar pretensiones relacionadas con la declaración de nulidad de un acto jurídico, a pesar que su actuación implica incidir en relaciones jurídicas de privados o particulares. Atendiendo a que garantizan que los actos emanados de estos sean conformes a los requisitos legales y el interés social, nos encontramos frente a un supuesto de legitimación extraordinaria, pues de forma excepcional se le habilita a interponer la demanda respectiva sin ser titular de los derechos sustantivos.

\subsection{La nulidad -del acto jurídico- ex officio}

Debe partirse por señalar que la segunda oración del artículo 220 del Código Civil no recoge una acción (o pretensión entendida según la doctrina) para que pueda habilitarse la legitimidad de las partes, sino una atribución al juzgador para declarar algo que es manifiestamente observable. Esta declaración se circunscribe a la apreciabilidad de una excepción material o sustantiva: la nulidad absoluta y manifiesta de un acto jurídico. Es trascendente el sentido que le otorga Lohmann (2019) a dicha oración:

A la necesidad de proteger este orden público, las buenas costumbres y, a la postre, esos intereses superiores, y para privar al acto jurídico de los efectos que negativamente podrían repercutir sobre todo ello, obedece el segundo párrafo del artículo 220 del Código Civil como excepción al principio de congruencia entre petitorio y fallo. ( $p$. 140)

Un sector de la doctrina considera que lo contemplado en el segundo párrafo del artículo 220 del Código Civil es una muestra del poder atribuido al juez para "excepcionar de oficio", pero de manera distinta al poder procesal del demandado; se considera, entonces, un poder de excepcionar supletorio (Morales, 2012). 
Otro sector no considera que sea un poder, sino una facultad del juez de emplear un "juicio de validez de oficio con el fin de establecer que el acto jurídico no incurra en una invalidez específica: la nulidad, pero no cualquier nulidad, sino una nulidad cualificada como es la nulidad manifiesta" (Torres, 2017, p. 129), y con ello, su contraste con los supuestos previstos en el artículo 219 del CC, desde una perspectiva de tutela de intereses generales.

También se ha sostenido que el artículo 220 no recoge propiamente una facultad del juez, pues frente a la detección de un vicio de nulidad absoluto y manifiesto, el juez no puede ser mero espectador, sino que tiene una obligación o deber, de tal manera que "pronunciarse, por ejemplo, respecto de la extensión de los efectos de un acto nulo, y peor aún, pretender que éstos se ejecuten, constituiría una suerte de complicidad del juez en el agravio al orden jurídico" (Jiménez, 2007, p. 7). Similar posición se asume al indicarse que la declaración de nulidad de oficio es excepcional, pero ello no enerva que el juez "no debe permitir la subsistencia del referido acto que notoriamente agravia bases elementales del sistema jurídico a las que el juez no puede sustraerse, ni podrá expedir sentencia ordenando la ejecución o cumplimiento de un acto jurídico que considera nulo" (Lohmann, 2002, p. 58).

Con el IX Pleno Casatorio Civil, la Corte Suprema confunde en la parte considerativa los términos facultad y poder, aunque se menciona en mayor medida el término poder para designar la atribución que realizó el legislador a favor del juez frente a actos jurídicos manifiestamente nulos. Así, es menester asociar el concepto facultad con licitud, pues implica que un determinado acto está permitido (o no prohibido) por la ley; a diferencia del concepto poder, que incide en el plano de la eficacia o resultado útil de un acto, modificando la realidad (Morales, 2008). Consideramos apropiado referirnos a un poder atribuido al juez, pues con este concepto se designa la capacidad del magistrado de modificar "algo", y en este sentido, se produce una modificación de la realidad con la declaración de oficio de la nulidad, evidenciándose ello en las situaciones jurídicas de las partes.

En este Pleno Casatorio también se estima a la nulidad manifiesta como aquella que "resulta evidente, patente, inmediatamente perceptible, en suma, aquella que resulta fácil de detectar sea que se desprenda del acto mismo o del examen de algún otro elemento de prueba incorporado al proceso". Se brindan algunos ejemplos que denotan el rango del alcance del artículo 220 del Código Civil, el cual es muy limitado: la falta de formalidad prescrita por ley bajo sanción de nulidad, contrato carente de seriedad, fin ilícito acreditado con sentencia penal firme, etc. Si bien se ha criticado la interpretación restrictiva de la teoría asumida por la Corte Suprema, discrepamos de esta opinión por cuanto la declaración de nulidad de oficio implica un poder supletorio, y como tal, amerita que la apreciabilidad del vicio sea de tal magnitud que permita sin dificultad su detección, y si se permitieran supuestos en donde el acervo probatorio no es lo suficientemente contundente, se incurriría en decisiones desacertadas por el deficiente uso de este mecanismo procesal.

\section{4. ¿Existe un límite temporal a la declaración de nulidad ex officio?}

La obscura y muy poco estudiada situación de la prescripción extintiva de la nulidad ex officio del acto jurídico debe analizarse sobre la base de la naturaleza jurídica de la nulidad de acto jurídico per se, como mecanismo de sanción al negocio inválido, y su plazo prescriptorio establecido en el numeral 1) del artículo $2001^{\circ}$ del Código civil de 1984. En ese orden, estructuraremos el objeto de análisis de este apartado desde tres perspectivas absolutamente definidas: i) análisis de la visión validadora del acto jurídico nulo como consecuencia del devenir del tiempo; ii) desconexión de la prescripción extintiva y la potestad nulificante de oficio; y, iii) la legalidad y seguridad jurídica que tiene como actor principal al juez que declara la nulidad ex officio del acto jurídico viciado.

\section{1 ¿Visión validadora del acto jurídico nulo?}

Se ha mencionado en algún sector de la doctrina nacional que, si la pretensión de nulidad prescribe, la consecuencia es que el juzgador no está habilitado para declararla, todo ello bajo el sustento de la prescripción, esto es, que si el acto viciado se regulariza con el tiempo, dicha situación de hecho no podrá ser tachada por el juez (Tantaleán, 2019). Para entender este primer supuesto fáctico es necesario poner en la palestra la posibilidad que, transcurrido el plazo para promover la pretensión de nulidad del acto jurídico, este entiéndase el acto- adquiere una eficacia tácita al no tener la posibilidad de ser cuestionada por el titular del derecho material. Con este comentario se pretende vincular el fenómeno prescriptorio al poder del juez de declarar la nulidad de oficio, entendiendo que los efectos de la prescripción recaen no solo en las partes 
dentro de la relación jurídica, sino también se extiende a las atribuciones del juzgador.

Así pues, Cuadros (1996) manifiesta que la prescripción [extintiva] de la nulidad tendría por objeto que el acto jurídico nulo adquiera validez por el transcurso del tiempo; situación que, habida cuenta, restringiría la posibilidad que tiene el juez de declarar la nulidad del acto viciado, por haber obtenido este, sobre la base de la inacción del titular, la validez que en su nacimiento adolecía por ausencia de algún elemento estructural. Debe tenerse claro, tal y como se ha precisado ut supra, que el acto jurídico que adolece de nulidad absoluta es aquella nulidad insalvable o radical, esto es, que tal defecto es gravísimo e insubsanable en la estructura del acto jurídico; tan importante y relevante que resulta imposible su subsanación, a pesar de que el sistema en general se esfuerza por conservar la eficacia y validez de los actos jurídicos. Por ello se dice que las causales de nulidad absoluta del acto jurídico son de orden público (Jiménez, 2007). Esa es la razón por la cual todo acto jurídico viciado en su estructura se encuentra en la imposibilidad jurídica de ser confirmado; derivando en la gravedad de este supuesto patológico.

Así también Paz Guillén (2014) comparte la posible convalidación del acto jurídico inválido en la medida que:

Según nuestro Código Civil, el acto jurídico es absolutamente nulo por cualquiera de las causales señaladas en el artículo 219ㅇ, puede, a los diez años, ser invulnerable y adquirir validez debido al tiempo cuando en otras legislaciones la nulidad no es convalidable ni siquiera por la prescripción de la acción. Por lo que consideramos que la prescripción de esta acción conlleva a una suerte de convalidación tácita futura. (p. 24)

Entonces, la consecuencia ipso iure que acarrea esta posición conllevaría sin duda alguna a que el Juez, como director del proceso, se encuentre en la imposibilidad material y jurídica de revisar un acto jurídico viciado, pues este ha obtenido esa validez que, aparentemente, le otorga el tiempo por la inacción del titular del derecho material, debiendo proceder a "sacramentar" o a darle esa investidura legal a aquél acto jurídico nulo al momento de emitir su decisión final, teniendo en consideración que la posibilidad de revisar estos actos se presentan cuando, precisamente, estos no han sido cuestionados por las partes de la relación jurídica material - procesal.
No compartimos los argumentos que estructuran esta posición, respetable por cierto, por considerarla no solo como una posición en la que el Juez resolverá las pretensiones originarias planteadas con una venda en los ojos, sino además la consideramos irremediablemente perjudicial para el derecho y la seguridad jurídica de nuestro país. La importancia de lo referido tiene como base la errónea proposición de que al transcurrir el plazo prescriptorio, el juzgador carece del poder para declarar la nulidad. $Y$ es esencial reafirmar esto porque el fenómeno prescriptorio incide únicamente en la pretensión, significando que aquel no puede, de ninguna manera, convalidar un acto nulo. Tampoco puede limitarse el espacio de actuación jurisdiccional solo para algunas causales de nulidad del artículo 219 del Código Civil, ya que estas no tienen carácter disponible o modificable, sino que responden a disposiciones de orden público, y como tales, requieren repulsa judicial.

Es imprescindible recordar que, en nuestra norma sustantiva, la nulidad es de pleno derecho. Se ha expuesto que "no requiere de una sentencia que así lo declare porque se trata de un acto jurídicamente inexistente, del que existe solo un hecho con la apariencia de acto, que es lo que hace necesario recurrir al órgano jurisdiccional" (Vidal, 2016, p. 630). Esta apariencia de validez del acto hace que en la realidad de ella surjan consecuencias (de ahí que surja el interés para recurrir al juez), pero esto no implica que el acto mismo deje de ser nulo de pleno derecho. El juez emitirá, consecuentemente, una sentencia declarativa que reconozca la nulidad, de manera que el paso del tiempo no convierte un acto viciado estructuralmente en un acto válido, al menos desde la perspectiva de la invalidez absoluta. Entonces, reiteramos, no es posible subsanar el acto nulo, y en instancia judicial "la sentencia no innova ni constituye una nueva situación jurídica, sino que pone de manifiesto la ineficacia que afectaba al contrato desde su celebración" (Diez-Picazo y Gullón, 2002, p. 104).

\subsection{Desconexión del fenómeno prescriptorio y la potestad nulificante}

El poder específico del juez con respaldo legal debe ser empleado dentro de sus límites, pero en el supuesto de la nulidad de oficio, el artículo 220 del Código Civil no establece ningún parámetro temporal para su ejercicio. Consideramos erróneo, por tanto, equiparar los fundamentos de la prescripción con el poder específico del juez, no solo por recaer en sujetos distintos, sino también porque el sustento de ambas figuras no es 
equivalente. Mientras la prescripción extintiva tiene como fundamento sancionar la inactividad del sujeto activo de una relación jurídica en aras de tutelar un interés privado, el poder del juez de declarar la nulidad se fundamenta en elementos de interés público que legitiman su intervención excepcional. De esa manera, una supuesta vinculación sin puntos de contacto no puede justificar la extensión de límites ni su aplicabilidad concreta.

Se debe observar que el decurso prescriptorio genera la extinción de la pretensión, aunque esto es relativo porque está sujeta a la alegación de la parte beneficiada con tal figura; por lo que es válida la declaración judicial de nulidad a petición de parte incluso superado el plazo legal para su invocación, en el supuesto de no haberse excepcionado procesalmente. Si esto es así, con mayor razón corresponde la declaración de oficio de nulidad de acto jurídico, pues al pasar de un ámbito privado a uno de orden público, el grado de lesividad al ordenamiento jurídico obliga al juzgador a no ser indiferente (o ser cómplice) frente a nulidades manifiestas, sin que ello signifique atender a limitaciones que están prestablecidas para supuestos distintos, es decir, cuando la nulidad sea alegada en vía de acción.

Aquí debe advertirse también que la prescripción atañe, según la voluntad del legislador, solo a la acción, que como hemos mencionado, debe entenderse como pretensión. Pero, no se hace referencia a la excepción, de manera que esta no se encuentra sujeta a dicho fenómeno. En doctrina se sostienen clasificaciones de excepciones, pero queremos considerar a la que tiene incidencia en el ámbito sustancial. En específico, la que se sustenta en los hechos impeditivos. Estos son aquellos que "impiden que el hecho, suficiente en sí para originar un derecho, lo origine" (Oertmann, 1933, p. 363), o dicho de otro modo, "imposibilitan el nacimiento de la relación jurídica o del derecho cuya existencia alega el demandante" (Fernández, 2012, p. 228). Al ser la nulidad un hecho impeditivo, y comprendiendo el poder del juez de excepcionar de oficio bajo tal premisa, no puede extenderse el fenómeno prescriptorio a dicha excepción por no existir previsión legal. En la misma línea se expone que "la prescripción de la acción no trae consigo la de la excepción (...), la acción y la excepción son dos remedios independientes" (Coviello, 2007, p. 539).

\subsection{La legalidad y seguridad jurídica}

Por lo pronto, afirmamos que al no haberse establecido en la legislación procesal o sustantiva civil un plazo para la actuación de la potestad nulificante de oficio frente a vicios manifiestos, no existen límites temporales del juzgador en dicho contexto. Si bien el numeral 1) del artículo $2001^{\circ}$ del Código civil establece el plazo de prescripción de la acción [Sic.] del acto jurídico, también lo es que, el artículo $220^{\circ}$ establece la posibilidad de que el Juez pueda, de oficio, declara dicha nulidad, no importando como tal el plazo que haya transcurrido desde el momento de la celebración hasta el momento del cuestionamiento realizado por aquél, pues debe entenderse que el citado precepto normativo, al hacer referencia a una nulidad absoluta, esta es nula ipso iure, máxime si ya hemos manifestado en el desarrollo de la presente que las causales contenidas en el artículo $219^{\circ}$ son de orden público.

Es decir, la posibilidad del Juez de conocer supuestos de hecho que contenga un acto jurídico que adolezca de vicio estructural -pudiendo observar este cuando resulte manifiesto- demuestra la defensa de la legalidad de nuestro ordenamiento jurídico. Esto no implica, sin duda alguna, dejar de lado a los sujetos que no participan en la relación sustantiva, aun cuando no haya norma jurídica limitativa de la potestad nulificante que evite posibles consecuencias negativas. Debe dejarse a salvo el derecho de los terceros para que, en amparo de su interés, puedan alegar la inoponibilidad de la invalidez absoluta, como una suerte de defensa frente a la denominada consolidación del negocio ineficaz por el mantenimiento del efecto socialmente producido (DíezPicazo, 1961). ¿Es todo este contexto saludable? Parecería que no, ya que puede afectar la seguridad en el tráfico, aunque también es factible alegar una protección implacable de la seguridad jurídica en el sentido de no investir de legalidad actos jurídicos nulos. Por ello, no es posible esgrimir una absoluta afectación.

Al tener naturaleza social las causales previstas en el 219 del CC, va más allá de las fronteras que constituye la autonomía privada; ese mundo imaginario creado por particulares para satisfacer sus necesidades, lo que conlleva, por sí mismo, a la imposibilidad jurídica de dotarle un "respirador artificial", y como tal, devolverle la vida a aquel acto nulo, que escapa de la disponibilidad de las partes. Por lo tanto, si bien existe la posibilidad de que el titular del derecho material pueda accionar cuestionando dicha anomalía jurídica, a pesar de haber fenecido con el devenir del tiempo, esto no es óbice para que el Juez, en defensa estricta de la seguridad 
jurídica, pueda revisar dentro de un proceso la validez del acto jurídico, ya sea de manera manifiesta o exhaustiva. Atribuirle un plazo de prescripción al poder del Juez de realizar una revisión estructural del acto, conllevaría, sin duda alguna, a una anarquía jurídica en el que todos los actos jurídicos nulos, cual zombies, adquieran vida para lograr los efectos jurídicos para los que estaban destinados de haber nacido sin anomalías patológicas en su estructura.

¿Existe alguna referencia externa que nos ayude a abarcar de otro modo lo expuesto? Consideramos ilustrativa la referencia al TUO de la Ley del Procedimiento Administrativo General. En esta se regula un plazo de dos años para la declaración de nulidad de oficio de los actos administrativos, contado desde la fecha en que quedan consentidos, según el artículo 213 inciso 3. Esta regulación puede servir de parámetro para una posterior limitación de la potestad nulificante de oficio en sede civil, sea en vía legislativa o interpretativa-judicial. Aunque en España, por ejemplo, la Ley 39/2015 en su artículo 106.1 establece que la revisión administrativa de actos nulos puede hacerse en cualquier momento, de manera tal que no existe límite temporal a esta potestad, sin perjuicio de indicarse que en vía jurisprudencial se la ha limitado en un balance entre seguridad jurídica y legalidad.

\section{Conclusiones}

A lo largo del trabajo se ha realizado un análisis de la prescripción, así como de la nulidad del acto jurídico, con la finalidad de desentrañar un posible límite temporal a la potestad del juez para declarar, de oficio, alguna nulidad manifiesta. La respuesta que hemos brindado es negativa: no es factible considerar que nuestra legislación civil y procesal civil contemple límite temporal a esta forma de excepcionar subsidiaria. Asimismo, se han manifestado razones sobre la imposibilidad de extensión de los plazos de la prescripción extintiva al supuesto del ejercicio de la potestad del juez ex officio.

Es preciso considerar las consecuencias que se puede extraer del criterio expuesto. Evidentemente, es trascendental para la seguridad jurídica tener las reglas claras, pues esto permitirá que los agentes puedan desenvolverse con confianza. Declarar la nulidad manifiesta de un acto que ha generado apariencia de legalidad por haber transcurrido en exceso el plazo para invocar la pretensión correspondiente, podría acarrear efectos negativos. Sin embargo, y esto también se ha definido en nuestro desarrollo, no es posible convalidar un acto nulo, de manera que el juzgador, ante una nulidad manifiesta, tiene la potestad de declararla. Será en cada caso particular donde se establezca con una adecuada motivación si procede la atemporalidad de la declaración judicial, o si prevalecen ulteriores razones que la enerven.

\section{Bibliografía}

Alsina, H. (1981). Tratado teórico práctico de derecho procesal civil y comercial (Tomo I). Buenos Aires, Argentina: EDIAR.

Ariano, E. (2007). Alegación de querer valerse de la prescripción. En Gaceta Jurídica (Ed.), Código Civil comentado (Tomo X) (pp.203-208). Lima: Gaceta Jurídica S.A.

Betti, E. (2018). Teoría general del negocio jurídico. Santiago de Chile, Chile: Ediciones Olejnik.

Campos García, H. A. (2016). Breves apuntes respecto de la "nulidad manifiesta" como presupuesto material de su "apreciabilidad" de oficio en el ordenamiento jurídico peruano. THEMIS Revista De Derecho, (70), 149-163. Recuperado a partir de http://revistas.pucp.edu.pe/index.php/themis/article/v iew/19609

Couture, Eduardo (1958). Fundamentos del Derecho Procesal Civil. Buenos Aires, Argentina: Roque Depalma Editor.

Coviello, Nicola (2007). Doctrina general del derecho civil. Lima, Perú: Ara editores.

Cuadros Villena, C. (1996). Acto jurídico. Curso elemental: Comentarios al Código Civil de 1984. Lima, Perú: Editora FECAT.

Díez-Picazo Y Ponce De León, L. (1961). Eficacia e ineficacia del negocio jurídico. Anuario de Derecho Civil, 14

https://dialnet.unirioja.es/servlet/articulo?codigo=204 $\underline{8946}$

Díez-Picazo, Luis y Gullón, Antonio (2002). Sistema de derecho civil (Vol. 2). Madrid, España: Editorial Tecnos.

Escobar, F. (2007a). Causales de nulidad absoluta. En Gaceta Jurídica (Ed.), Código Civil comentado (Tomo I) (pp. 675-688). Lima: Gaceta Jurídica S.A. 
Escobar, F. (2007b). Nulidad absoluta. En Gaceta Jurídica (Ed.), Código Civil comentado (Tomo I) (pp. 689691). Lima: Gaceta Jurídica S.A.

Fernández López, M. (2012). El Juez Civil y el Hecho Incierto. Un Estudio desde la Perspectiva de los Principios de Facilidad y Disponibilidad Probatoria. Derecho \& Sociedad, (38), 176-184. Recuperado a partir de

http://revistas.pucp.edu.pe/index.php/derechoysocied ad/article/view/13117

Jiménez Vargas-Machuca, R. (2007). La nulidad del acto jurídico declarada de oficio por el juez. JUS, Doctrina \& Práctica,

http://www2.congreso.gob.pe/Sicr/AsesJuridica/JURIDI CA.NSF/vf12web/B163FF1A3C1532EA052572FA006B7 BD1/\$FILE/La nulidad del acto juridico.pdf

Larenz, K. (2019). Derecho Civil. Parte General. Santiago de Chile, Chile: Ediciones Olejnik.

Ledesma, M. (2008). Comentarios al Código procesal civil. Lima, Perú: Gaceta Jurídica S.A.

León, L. (2019). Derecho privado. Parte general. Negocios, actos y hechos jurídicos. Lima, Perú: Fondo Editorial PUCP.

Linares, N. G. (2007). Derecho civil patrimonial. Lima, Perú: Palestra Editores.

Lohmann Luca de Tena, J. G. (2002). La nulidad manifiesta: su declaración judicial de oficio. IUS ET VERITAS, 12(24), 56-63. Recuperado a partir de http://revistas.pucp.edu.pe/index.php/iusetveritas/arti cle/view/16169

Lohmann Luca de Tena, J. G. (2019). Estudios claves de derecho civil. Lima, Perú: Gaceta Jurídica S.A.

Morales Hervias, R. (2008). Situaciones jurídicas subjetivas.

Advocatus,

(19).

https://doi.org/10.26439/advocatus2008.n019.478

Morales, Rómulo (2012). La inconsistente "declaración" de oficio de la nulidad del contrato en el Código Civil peruano de 1984. Actualidad Jurídica, (219).

Morales Godo, J. (2010). La función del juez en una sociedad democrática. Revista De La Maestría En
Derecho Procesal, 4(1). Recuperado a partir de http://revistas.pucp.edu.pe/index.php/derechoprocesa I/article/view/2397

Morales, J. (2007). Alegación de la suspensión e interrupción. En Gaceta Jurídica (Ed.), Código Civil comentado (Tomo X) (pp.233-238). Lima: Gaceta Jurídica S.A.

Oertmann, P. (1933). Introducción al derecho civil. Barcelona, España: Editorial Labor S.A.

Osterling, F. (2007). Las Obligaciones. Lima, Perú: Editora Jurídica Grijley.

Paz Guillén, A. (2014). La acción de nulidad y la impugnación de los acuerdos societarios, legitimación, procesos y caducidad en la ley general de sociedades (Tesis de Maestría). Pontificia Universidad Católica del Perú, Lima, Perú. Recuperado de http://hdl.handle.net/20.500.12404/5611

Prado Bringas, R., \& Zegarra Valencia, O. F. (2018). La legitimación en el proceso civil peruano. IUS ET VERITAS, (56), 44-60. https://doi.org/10.18800/iusetveritas.201801.003

Taboada Córdova, L. (1988). Causales de nulidad del acto jurídico. THEMIS Revista De Derecho, (11), 71-76. Recuperado a partir de http://revistas.pucp.edu.pe/index.php/themis/article/v iew/10746

Tantaleán, Reynaldo (2019). La nulidad del acto jurídico y las incoherencias en su tratamiento. Lima, Perú: Instituto Pacífico.

Torres Vásquez, A. (2017). Nulidad declarada de oficio. IX Pleno Casatorio Civil. Lex, (19). https://dialnet.unirioja.es/servlet/articulo?codigo $=604$ $\underline{3555}$

Vidal Ramírez, F. (2016). El acto jurídico. Lima, Perú: Instituto Pacífico.

Vidal Ramírez, F. (2014). Precisiones en torno a la prescripción extintiva y a la caducidad. LEX - REVISTA DE LA FACULTAD DE DERECHO Y CIENCIAS POLÍTICAS, 11(11), 117-128. doi:http://dx.doi.org/10.21503/lex.v11i11.6 